\title{
ENVIRONMENTAL CONSEQUENCES OF WILDLIFE TOURISM: THE USE OF FORMALISED QUALITATIVE MODELS
}

\author{
ŠTĚPÁN VESELY๋̌, MIRKO DOHNAL
}

Department of Economics, Faculty of Business and Management, Brno University of Technology, Kolejní 4, 61200 Brno, Czech Republic; e-mail: stepan.vesely@seznam.cz, dohnal@fbm.vutbr.cz

${ }^{*}$ Author for correspondence

\begin{abstract}
Veselý Š., Dohnal M.: Environmental consequences of wildlife tourism: the use of formalised qualitative models. Ekológia (Bratislava), Vol. 34, No. 3, p. 260-267, 2015.

The paper presents a simple qualitative model of environmental consequences of wildlife tourism. Qualitative models use just three values: Positive/Increasing, Zero/Constant and Negative/Decreasing. Such quantifiers of trends are the least information intensive. Qualitative models can be useful, since models of wildlife tourism include such variables as, for example, Biodiversity (BIO), Animals' habituation to tourists (HAB) or Plant composition change (PLA) that are sometimes difficult or costly to quantify. Hence, a significant fraction of available information about wildlife tourism and its consequences is not of numerical nature, for example, if $H A B$ is increasing then $B I O$ is decreasing. Such equationless relations are studied in this paper. The model has 10 variables and 20 equationless pairwise interrelations among them. The model is solved and 15 solutions, that is, scenarios are obtained. All qualitative states, including the first and second qualitative derivatives with respect to time, of all variables are specified for each scenario.
\end{abstract}

Key words: tourism, human impact, formalisation, qualitative model, multidimensional model, scenarios.

\section{Introduction}

The popularity of wildlife tourism (WT) has been growing in recent decades (e.g., Giannecchini, 1993; Ballantyne et al., 2009; Knight, 2009) and its importance has become more salient in economic terms (e.g., Orams, 2002). The task of the present paper is to outline a formalised qualitative model (FQM) of certain environmental consequences of WT.

WT is an interdisciplinary and multidimensional problem (e.g., Reynolds, Braithwaite, 2001; Semeniuk et al., 2010; Catlin et al., 2011). Some of the factors pertaining to WT and/ or their impact are ill-known (e.g., Rodger et al., 2009); there is information shortage. Information shortage can be eliminated by additional information sources including additional measurements, which are usually time consuming and costly, or by the utilisation of such information items, that is, qualitative data, which cannot be easily treated by conventional formal tools, but can be treated by qualitative modelling. 
FQMs capture relationships among variables in the form of degraded (simplified) equations and statistical relations and/or in the form of common-sense heuristics (e.g., if X goes up, Y goes down with increasing rapidity). Qualitative methodology (e.g., Kuipers, 1989; Dohnal, 1991; Trave-Massuyes et al., 2003) has been used in some form to model, for example, complex engineering systems (e.g., Hurme et al., 1993), investment decisions and economic problems (e.g., Benaroch, Dhar, 1995; Bohanec et al., 1995; Hinkkanen et al., 2003), various chaotic systems (Vícha, Dohnal, 2008a,b) and also problems related to ecology and environment (Salles et al., 2006a,b; Noble et al., 2009). See Bourseau et al. (1995), De Jong (2004) and Price et al. (2006) for an overview.

Note that qualitative modelling can be seen as one of the 'uncertainty calculi', such as fuzzy sets (e.g., Dubois, Prade, 1991; Oblak, Zadnik Stirn, 2000; Van Broekhoven et al., 2006), rough sets (e.g., Pawlak, 1982) and order of magnitude reasoning (e.g., Raiman, 1991). Qualitative models capture the fundamental features of a system under study, while eliminating quantitative detail; see, for example, Kuipers (1989). Qualitative models can minimise or completely eliminate problems related to the identification of constants in conventional sets of equations, if qualitative results are acceptable; see, for example, Keesman (2011).

\section{Methods}

\section{Qualitative models}

There are only three qualitative values: positive, zero and negative. The symbols used are,+ 0 and -, respectively. A qualitative scenario of a qualitative model is specified if all its $n$ qualitative variables $\mathrm{X} \equiv\left(\mathrm{X}_{1}, \mathrm{X}_{2}, \ldots, \mathrm{X}_{n}\right)$ are described by the qualitative triplets (X, DX, DDX), where DX and DDX are the first qualitative and second qualitative derivatives with respect to time (or an independent variable in general). Let us suppose that the triplet $(++0) \equiv(\mathrm{T}$, DT, DDT) represents WT popularity $\mathrm{P}(t)$ as a function of time: it means that the popularity is positive $(\mathrm{P}=+)$, it is increasing in this example $(\mathrm{DP}=+)$ and the increase is linear $(\mathrm{DDP}=0)$ as the second derivative is zero.

A typical example of a qualitative knowledge item can be formalised by a certain simple relation between two variables $\mathrm{X}$ and $\mathrm{Y}$. For example:

If the price $\mathrm{X}$ of a product is decreasing then the demand $\mathrm{Y}$ is increasing.

If the price $\mathrm{X}$ of a product is increasing then the demand $\mathrm{Y}$ is decreasing. However, the demand Y cannot decrease infinitely; it means that a certain positive quantitatively unknown lower limit exists.

A formal interpretation of the qualitative knowledge items (1) and (2) is DY/DX $=-$ [see (1)] and DDY/DDX = $+[$ see (2)], where DY/DX is the first qualitative derivative with respect to X and DDY/DDX is the second derivative.

Typical examples of qualitative relations are given in Fig. 1.

The identification numbers given in Fig. 1 are shape codes for the respective qualitative shapes; for example, 21 is a code number for the function characterised by a positive value of $\mathrm{Y}$ and positive first and second qualitative derivatives of $\mathrm{Y}$ with respect to $\mathrm{X}$ (triplet +++ ).

\footnotetext{
If the second derivative is not known then there are two variants of qualitative proportionality:

$\mathrm{M} \_+$If $\mathrm{X}$ is increasing then $\mathrm{Y}$ is increasing. If $\mathrm{X}$ is decreasing then $\mathrm{Y}$ is decreasing.

$\mathrm{M}_{\text {-- }}$ If $\mathrm{X}$ is increasing then $\mathrm{Y}$ is decreasing. If $\mathrm{X}$ is decreasing then $\mathrm{Y}$ is increasing.

For more details, see, for example, Kuipers (1989), Dohnal (1991), Trave-Massuyes et al. (2003).
} 

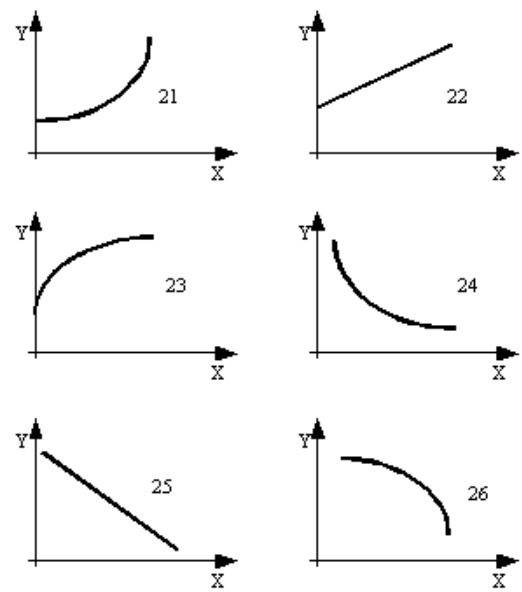

Fig. 1. Examples of pairwise qualitative equationless relations.

Qualitative vector optimisation

It is not the goal of this paper to study the algorithm how to solve qualitative models, that is, how the software selects/rejects scenarios, so we will not go into much detail here. It is a combinatorial problem. The most trivial algorithm is based on systematic confrontation of all possible $n$-dimensional triplets (e.g., $++-,++0,+0+)$ for each variable and the model itself. This type of solution is called brutal force in artificial intelligence. For more details, see, for example, Parsons, Dohnal (1995), Trave-Massuyes et al. (2003) and Vícha, Dohnal (2008a,b).

Let us suppose that there are two independent variables $\mathrm{X}_{1}, \mathrm{X}_{2}$ and two objective functions $\mathrm{Q}_{1}, \mathrm{Q}_{2}$. For example, the first objective function is Profit and the second is Safety. We want both objective functions to be maximised.

There is a vector $\mathrm{F}$ of constraints represented by a set of equationless relations:

$$
\mathrm{F}\left(\mathrm{X}_{1}, \mathrm{X}_{2}, \mathrm{Q}_{1}, \mathrm{Q}_{2}\right)=0
$$

Let us presuppose that qualitative model (4) has the following set of three solutions (scenarios):

$\begin{array}{cllll}\text { Scenario no. } & \mathrm{X}_{1} & \mathrm{X}_{2} & \mathrm{Q}_{1} & \mathrm{Q}_{2} \\ 1 & +++ & +++ & +- & +- \\ 2 & ++- & +-- & +++ & +- \\ 3 & +-- & +-+ & +-+ & +++\end{array}$

Since we want $\mathrm{Q}_{1}$ and $\mathrm{Q}_{2}$ to be maximised, the first qualitative solution [see (5) - scenario no. 1] is highly undesirable, because both objective functions decrease if independent variables $\mathrm{X}_{1}$ and $\mathrm{X}_{2}$ follow the qualitative pattern given in scenario no. 1 in (5).

If there were a set of scenarios that contain, for example, the following solution

$\begin{array}{llll}\mathrm{X}_{1} & \mathrm{X}_{2} & \mathrm{Q}_{1} & \mathrm{Q}_{2} \\ ++- & +-0 & +++ & +++\end{array}$

then scenario (6) would be highly desirable because this scenario maximises both objective functions in the best possible way, that is, both second derivatives are positive.

\section{Results and discussion}

WT can be characterised by the following set (7) of 10 variables: 9 independent variables and 1 objective function. Set (7) is partially adapted from Reynolds and Braithwaite (2001).

Objective function:

BIO Biodiversity

Independent variables:

TOU Level of wildife tourism

HAB Animals habituation to tourists - see, for example, Orams (2002), Knight (2009) and Higham, Shelton (2011). 
$A B E$ Aberrant social behaviour of animals and/or modification of activity patterns - see, for example, Lott, McCoy (1995), Lusseau (2003) and Semeniuk et al. (2010).

DEA Level of human incurred deaths/injuries/disease of animals - see, for example, Laist et al. (2001), Orams (2002) and Semeniuk et al. (2010).

POL Level of pollution - see, for example, Reynolds, Braithwaite (2001).

PLA Plant composition change - see, for example, Reynolds, Braithwaite (2001).

PRE Level of predation - see, for example, Reynolds, Braithwaite (2001), Orams (2002) and Beale, Monaghan (2005).

MIG Animal migration - see, for example, Reynolds, Braithwaite (2001) and Semeniuk et al. (2010).

REP Animals' reproductive success - see, for example, Yorio et al. (2001), Lusseau (2003) and Ballantyne et al. (2009).

The list of variables is still relatively short to keep the complexity of the model appropriate for publication. However, other variables of interest could be easily included into the FQM.

\section{Qualitative model of WT environmental consequences}

The following set (8) of pairwise qualitative relations is used to formalise relations among the set of variables (7). The set of interrelations is inspired by many dialogues with a team of experts and by Reynolds, Braithwaite (2001), Catlin et al. (2011) and the studies quoted above in (7).

The qualitative model is represented by the following set of relations (see Fig. 1 for the qualitative shapes):

\begin{tabular}{llll} 
Shape & & \multicolumn{2}{c}{$Y$ (see Fig. 1) } \\
1 & 24 & DEA & BIO \\
2 & 24 & POL & BIO \\
3 & 24 & PLA & BIO \\
4 & 24 & PRE & BIO \\
5 & 23 & REP & BIO \\
6 & 21 & HAB & TOU \\
7 & M_+ [see (3)] & ABE & TOU \\
8 & $M_{-}+$ & DEA & TOU \\
9 & $M_{-}+$ & POL & TOU \\
10 & 21 & PLA & TOU \\
11 & 21 & MIG & TOU \\
12 & $M_{-}+$ & ABE & HAB \\
13 & $M_{-}+$ & PRE & HAB \\
14 & 21 & PRE & ABE \\
15 & 24 & REP & ABE \\
16 & 23 & POL & DEA \\
17 & 24 & REP & DEA
\end{tabular}




$\begin{array}{llll}18 & \text { M_+ }_{-} & \text {PLA } & \text { POL } \\ 19 & \text { M_+ }^{+} & \text {MIG } & \text { PRE } \\ 20 & 24 & \text { REP } & \text { PRE }\end{array}$

\section{Scenarios}

The set of 15 scenarios - see Table 1 - is generated using software described in Vícha and Dohnal (2008a,b). Different qualitative problems can be easily solved using the set of scenarios that represent a complete description of all possible behaviours within the modelled system.

T a b le 1. Wildlife tourism scenarios.

\begin{tabular}{|l|l|l|l|l|l|l|l|l|l|l|l|l|}
\hline \multirow{2}{*}{ Scenario } & \multicolumn{9}{|c|}{ Variables $[\mathrm{see}(7)]$} \\
\cline { 2 - 14 } & BIO & TOU & HAB & ABE & DEA & POL & PLA & PRE & MIG & REP \\
\hline 1 & +++ & +-+ & +-+ & +-+ & +-+ & +-+ & +-+ & +-+ & +-+ & +++ \\
\hline 2 & +++ & +-- & +-- & +-- & +-- & +-- & +-- & +-- & +-- & +++ \\
\hline 3 & ++0 & +-+ & +-+ & +-+ & +-+ & +-+ & +-+ & +-+ & +-+ & +++ \\
\hline 4 & ++- & +-+ & +-+ & +-+ & +-+ & +-+ & +-+ & +-+ & +-+ & +++ \\
\hline 5 & ++- & +-+ & +-+ & +-+ & +-+ & +-+ & +-+ & +-+ & +-+ & ++0 \\
\hline 6 & ++- & +-+ & +-+ & +-+ & +-+ & +-+ & +-+ & +-+ & +-+ & ++- \\
\hline 7 & $+0+$ & $+0-$ & $+0-$ & $+0-$ & $+0-$ & $+0-$ & $+0-$ & $+0-$ & $+0-$ & $+0+$ \\
\hline 8 & +00 & +00 & +00 & +00 & +00 & +00 & +00 & +00 & +00 & +00 \\
\hline 9 & $+0-$ & $+0+$ & $+0+$ & $+0+$ & $+0+$ & $+0+$ & $+0+$ & $+0+$ & $+0+$ & $+0-$ \\
\hline 10 & +-+ & +++ & +++ & +++ & +++ & +++ & +++ & +++ & +++ & +-+ \\
\hline 11 & +-+ & ++- & ++- & ++- & ++- & ++- & ++- & ++- & ++- & +-+ \\
\hline 12 & +-0 & +++ & +++ & +++ & +++ & +++ & +++ & +++ & +++ & +-+ \\
\hline 13 & +- & +++ & +++ & +++ & +++ & +++ & +++ & +++ & +++ & +-+ \\
\hline 14 & +-- & +++ & +++ & +++ & +++ & +++ & +++ & +++ & +++ & +-0 \\
\hline 15 & +-- & +++ & +++ & +++ & +++ & +++ & +++ & +++ & +++ & +- \\
\hline
\end{tabular}

All variables (7) are positive because of their very nature. Therefore the first values in all triplets (in Table 1) are always equal to + . For example, scenario 8 is a steady state situation. All the first and second derivatives are zeros. Therefore nothing happens; there are no changes in time.

Scenarios 1-2 indicate that BIO increases more and more quickly as a function of time, while, for example, TOU and HAB go down. Scenarios 13-15 give the opposite. There are, however, some differences in the precise character of the increase/decline of the variables with respect to the second derivatives. For example, in scenario 2, TOU declines more and more quickly (TOU is characterised by triplet +-- in scenario 2), whereas in scenario 1 TOU declines with a decreasing rapidity (TOU is characterised by triplet +-+ in scenario 1).

The scenarios obtained could be interpreted according to the qualitative vector optimisation method described in section Qualitative vector optimisation. The nature of the objective function (BIO) probably requires maximisation; hence, there are six relatively favourable scenarios, that is, scenarios 1-6 and six relatively undesirable ones, scenarios 10-15. 
We can say that the present model is well specified by the interrelations given in (8), which causes it to be quite restrictive, that is, there is relatively little variability in the scenarios obtained. If less input knowledge [such as (8)] were available, the model would be less well specified and consequently less restrictive, and more variability would be encountered in the scenarios obtained (e.g., certain variables would be linked to certain other variables positively in a given subset of scenarios and negatively in another subset). For example, when only every other interrelation (i.e., $1,3,5, \ldots, 19)$ given in (8) was entered in the model, we obtained 125 possible scenarios. Relatively less restrictive models will be generated when more uncertain and/or more ambiguous determinants of WT are included in them.

Different modifications of the current FQM might be needed, because WT effects are often difficult to assess, ambiguous and location- or species-specific. For example, although the presence of tourists often lowers animals' reproductive success (e.g., Yorio et al., 2001; Lusseau, 2003; Ballantyne et al., 2009), it can also facilitate animals' reproduction in some cases (e.g., Boutin, 1990; Svensson, Nilsson, 1995). The changes caused by tourists need not always be negative (e.g., Wilson, Tisdell, 2001; Orams, 2002; Tisdell, Wilson, 2002).

The present model is also still quite simple. For instance, not only the number of tourists, but also their characteristics, wants and needs could be included in prospective FQMs of WT (see, e.g., Ballantyne et al., 2009; Semeniuk et al., 2010; Catlin et al., 2011).

The obvious limitation of FQMs is that qualitative reasoning can answer qualitative queries only (see section Qualitative models), not quantitative ones, and thus can serve just as a supplement to the existing quantitative methods (and/or as a rigorous formalisation of qualitative methods, such as case studies). However, inclusion of mathematical equations into qualitative models is possible; see Dohnal (1992) and Vícha, Dohnal (2008a,b). Also, it is possible to calculate all possible transitions between the qualitative scenarios (see, e.g., Režňáková et al., 2012).

Apart from the assessment of WT consequences, FQMs can assist academics and practitioners in modelling WT antecedents (e.g., affordability, popularity, media coverage, word of mouth), as well as in the evaluation of different WT management practices, such as regulatory and educational methods (see, e.g., Orams, 1996; Orams, Hill, 1998; Barančok, Barančoková, 2008; Figueras et al., 2011).

\section{Conclusion}

Qualitative approach has much to offer when highly complex and/or partially vague problems such as WT are examined. In the present study of environmental consequences of WT, we generated an FQM consisting of 15 possible scenarios. The model obtained is definitely not the only possible alternative. Many modifications, upgrades and extensions are possible. The paper presents only methodology and a simple model as a demonstration. FQMs can supplement established tools for WT analysis with very little additional cost. This might be profitable especially under information shortage, measurement difficulties, time pressure to make decisions and/or uncertainty, or when several novel and/or difficult to measure (e.g., qualitative only) variables are being considered. 


\section{References}

Ballantyne, R., Packer, J. \& Hughes K. (2009). Tourists' support for conservation messages and sustainable management practices in wildlife tourism experiences. Tourism Management, 30, 658-664. DOI:10.1016/j.tourman.2008.11.003.

Barančok, P. \& Barančoková M. (2008). Evaluation of the tourist path carrying capacity in the Belianske Tatry Mts. Ekológia (Bratislava), 27, 401-420.

Beale, C.M. \& Monaghan P. (2005). Modeling the effects of limiting the number of visitors on failure rates of seabird nests. Conserv. Biol., 19, 2015-2019. DOI: 10.1111/j.1523-1739.2005.00256.x.

Benaroch, M. \& Dhar V. (1995). Controlling the complexity of investment decisions using qualitative reasoning techniques. Decision Support Systems, 15, 115-131. DOI: 10.1016/0167-9236(94)00031-M.

Bohanec, M., Rajkovič, V., Semolić, B. \& Pogačnik A. (1995). Knowledge-based portfolio analysis for project evaluation. Information \& Management, 28, 293-302. DOI: 10.1016/0378-7206(94)00048-N.

Bourseau, P., Bousson, K., Dague, P., Dormoy, J.-L. et al. (1995). Qualitative reasoning: A survey of techniques and applications. AI Communications, 8, 119-192. DOI: 10.3233/AIC-1995-83-401.

Boutin, S. (1990). Food supplementation experiments with terrestrial vertebrates: Patterns, problems, and the future. Can. J. Zool., 68, 203-220. DOI: 10.1139/z90-031.

Catlin, J., Jones, R. \& Jones T.S. (2011). Revisiting Duffus and Dearden's wildlife tourism framework. Biol. Conserv. 144, 1537-1544. DOI: 10.1016/j.biocon.2011.01.021.

De Jong, H. (2004). Qualitative simulation and related approaches for the analysis of dynamic systems. Knowledge Engineering Review, 19, 93-132. DOI: 10.1017/S0269888904000177.

Dohnal, M. (1991). A methodology for common-sense model development. Computers in Industry, 16, 141-158.

Dohnal, M. (1992). Qualitative partial differential equations and their realistic applications. Computers in Industry, 20, 209-217.

Dubois, D. \& Prade H. (1991). Fuzzy sets in approximate reasoning, part 1: Inference with possibility distributions. Fuzzy Sets and Systems, 40, 143-202.

Figueras, M.T.B., Farrés, M.C.P. \& Pérez G.R. (2011). The carrying capacity of cycling paths as a management instrument. The case of Ebro delta (Spain). Ekológia (Bratislava), 30, 438-452. DOI: 10.4149/ekol_2011_04_397.

Giannecchini, J. (1993). Ecotourism: New partners, new relationships. Conserv. Biol., 7, 429-432. DOI: 10.1046/j.1523-1739.1993.07020429.x.

Higham, J.E.S. \& Shelton E.J. (2011). Tourism and wildlife habituation: Reduced population fitness or cessation of impact? Tourism Management, 32, 1290-1298. DOI: 10.1016/j.tourman.2010.12.006.

Hinkkanen, A., Lang, K.R. \& Whinston A.B. (2003). A set-theoretical foundation of qualitative reasoning and its application to the modeling of economics and business management problems. Information Systems Frontiers, 5, 379-399. DOI: 10.1023/B:ISFI.0000005652.72048.4d.

Hurme, M., Jarvelainen, M., Parsons, S. \& Dohnal M. (1993). A qualitative commonsense method for optimization of complex engineering systems. Engineering Optimization, 20, 323-339. DOI: 10.1080/03052159308941288.

Keesman, K.J. (2011). System identification. London: Springer. DOI: 10.1007/978-0-85729-522-4.

Knight, J. (2009). Making wildlife viewable: Habituation and attraction. Society \& Animals, 17, 167-184. DOI: $10.1163 / 156853009 X 418091$.

Kuipers, B. (1989). Qualitative reasoning: Modeling and simulation with incomplete knowledge. Automatica, 25, 571-585.

Laist, D.W., Knowlton, A.R., Mead, J.G., Collet, A.S. \& Podesta M. (2001). Collisions between ships and whales. Mar. Mamm. Sci., 17, 35-75. DOI: 10.1111/j.1748-7692.2001.tb00980.x.

Lott, D.F. \& McCoy M. (1995). Asian rhinos Rhinoceros unicornis on the run: Impact of tourist visits on one population. Biol. Conserv., 73, 23-26. DOI: 10.1016/0006-3207(95)90053-5.

Lusseau, D. (2003). Effects of tour boats on the behavior of bottlenose dolphins: Using Markov chains to model anthropogenic impacts. Conserv. Biol., 17, 1785-1793. DOI: 10.1111/j.1523-1739.2003.00054.x.

Noble, R.A.A., Bredeweg, B., Linnebank, F., Salles, P. \& Cowx I.G. (2009). A qualitative model of limiting factors for a salmon cycle in the context of river rehabilitation. Ecological Informatics, 4, 299-319. DOI: 10.1016/j. ecoinf.2009.09.006.

Oblak, L. \& Zadnik Stirn L. (2000). The possibility of solving economic and environmental protection problems in wood industry companies by the application of the method of fuzzy goal programming. Ekologia (Bratislava), 19, 409-419. 
Orams, M.B. (1996). A conceptual model of tourist-wildlife interaction: The case for education as a management strategy. Aust. Geogr., 27, 39-51.DOI: 10.1080/00049189608703156.

Orams, M.B. \& Hill G.J.E. (1998). Controlling the ecotourist in a wild dolphin feeding program: Is education the answer? Journal of Environmental Education, 29(3), 33-38. DOI: 10.1080/00958969809599116.

Orams, M.B. (2002). Feeding wildlife as a tourism attraction: a review of issues and impacts. Tourism Management, 23, 281-293. DOI: 10.1016/S0261-5177(01)00080-2.

Parsons, S. \& Dohnal M. (1995). The qualitative and semiqualitative analysis of environmental problems. Environmental Software, 10, 75-85. DOI: 10.1016/0266-9838(95)00008-9.

Pawlak, Z. (1982). Rough sets. International Journal of Computer and Information Sciences, 11, 341-356. DOI: $10.1007 /$ BF01001956.

Price, C.J., Travé-Massuyés, L., Milne, R., Ironi, L., Forbus, K., Bredeweg, B., Lee, M.H., Struss, P., Snooke, N., Lucas, P., Carazza, M. \& Coghill G.M. (2006). Qualitative futures. Knowledge Engineering Review, 21, 317-334. DOI: $10.1017 /$ S026988890600097X.

Raiman, O. (1991). Order of magnitude reasoning. Artificial Intelligence, 51, 11-38. DOI: 10.1016/00043702(91)90107-U.

Reynolds, P.C. \& Braithwaite D. (2001). Towards a conceptual framework for wildlife tourism. Tourism Management, 22, 31-42. DOI: 10.1016/S0261-5177(00)00018-2.

Režňáková, M., Wouters, H., Dohnal, M. \& Brož Z. (2012). Equationless qualitative models of science parks: Part II, optimisation by time sequences of scenarios. International Journal of Technology Intelligence and Planning, 8, 295-306. DOI: 10.1504/IJTIP.2012.048575.

Rodger, K., Moore, S.A. \& Newsome D. (2009). Wildlife tourism, science and actor network theory. Annals of Tourism Research, 36, 645-666. DOI: 10.1016/j.annals.2009.06.001.

Salles, P., Bredeweg, B. \& Araujo S. (2006a). Qualitative models about stream ecosystem recovery: Exploratory studies. Ecol. Model., 194, 80-89. DOI: 10.1016/j.ecolmodel.2005.10.018.

Salles, P., Bredeweg, B. \& Bensusan N. (2006b). The ants' garden: Qualitative models of complex interactions between populations. Ecol. Model., 194, 90-101. DOI: 10.1016/j.ecolmodel.2005.10.004.

Semeniuk, C.A.D., Haider, W., Cooper, A. \& Rothley K.D. (2010). A linked model of animal ecology and human behavior for the management of wildlife tourism. Ecol. Model., 221, 2699-2713. DOI: 10.1016/j.ecolmodel.2010.07.018.

Svensson, E. \& Nilsson J.A. (1995). Food-supply, territory quality, and reproductive timing in the blue tit (Parus Caeruleus). Ecology, 76, 1804-1812. DOI: 10.2307/1940712.

Tisdell, C. \& Wilson C. (2002). Ecotourism for the survival of sea turtles and other wildlife. Biodivers. Conserv., 11, 1521-1538. DOI: 10.1023/A:1016833300425.

Trave-Massuyes, L., Ironi, L. \& Dague P. (2003). Mathematical foundations of qualitative reasoning. AI Magazine, 24, 91-106. DOI: 10.1609/aimag.v24i4.1733.

Van Broekhoven, E., Adriaenssens, V., De Baets, B. \& Verdonschot P.F.M. (2006). Fuzzy rule-based macroinvertebrate habitat suitability models for running waters. Ecol. Model., 198, 71-84. DOI: 10.1016/j.ecolmodel.2006.04.006.

Vícha, T. \& Dohnal M. (2008a). Qualitative feature extractions of chaotic systems. Chaos, Solitons \& Fractals, 38, 364-373. DOI: 10.1016/j.chaos.2008.01.008.

Vícha, T. \& Dohnal M. (2008b). Qualitative identification of chaotic systems behaviours. Chaos, Solitons \& Fractals, 38, 70-78. DOI: 10.1016/j.chaos.2008.01.027.

Wilson, C. \& Tisdell C. (2001). Sea turtles as a non-consumptive tourism resource especially in Australia. Tourism Management, 22, 279-288. DOI: 10.1016/S0261-5177(00)00059-5.

Yorio, P., Frere, E., Gandini, P. \& Schiavini A. (2001). Tourism and recreation at seabird breeding sites in Patagonia, Argentina: Current concerns and future prospects. Bird Conserv. Int., 11, 231-245. DOI: 10.1017/ S0959270901000314. 